\title{
Etnogênese e movimento indígena: lutas políticas e identitárias na virada do século XX para o XXI
}

\author{
João Francisco Kleba Lisboa \\ Universidade de Brasília - UnB \\ e-mail: jfklisboa@gmail.com
}

\begin{abstract}
Resumo
Neste artigo procuro retomar o debate em torno da noção de etnogênese, estendendo-o ao contexto histórico da América Latina e do Caribe e relacionando-o à categoria de Povos Indígenas, utilizada por movimentos de cunho étnico-político (mas que se diferenciam de movimentos de cunho nacionalista) ao redor do mundo. Aquilo que Lévi-Strauss chamou de aquecimento das sociedades indígenas no final do século $\mathrm{XX}$, e que outros autores descrevem como um despertar do movimento indígena, continua a provocar debates dentro e fora do meio acadêmico. Fruto do contato direto com os colonizadores, mas indicando um movimento reverso de retomada de terras e direitos, assim como de símbolos, autoestima e orgulho nativo, tais movimentos contemporâneos estariam imbricados nas diferentes reivindicações de identidade étnica que passaram a configurar a assim chamada etnogênese, redobrando a preocupação dos Estados com tais novas formas de organização política, como é o caso do contexto brasileiro aqui abordado.
\end{abstract}

Palavras-chave: etnogênese, movimento indígena, identidade, destino.

\begin{abstract}
In this article I attempt to retake the debate around the notion of ethnogenesis, extending it to the historical context of Latin America and the Caribbean and relating it to the category of Indigenous Peoples, used by ethnic-political movements (but differing itself from movements of nationalistic character) around the world. What Lévi-Strauss called the warm-up of indigenous societies at the end of the twentieth century, which other authors describe as an awakening of the indigenous movement, continues to provoke debates within and outside academia. As a result of direct contact with the colonizers, but indicating a reverse movement of land and rights, as well as of symbols, self-esteem and native pride, such contemporary movements are imbricated in the different claims of ethnic identity that came to form the so-called ethnogenesis, redoubling in turn the concern of States with such new forms of political organization, such as the Brazilian case that is addressed here.
\end{abstract}

Keywords: ethnogenesis, indigenous movement, identity, destiny.

\section{Introdução}

Aproveito esta oportuna publicação do "Dossiê LAGERI 20 anos" para, em vez de apresentar um caso pontual de pesquisa recente ou em andamento, abordar um dos temas centrais que permeiam a produção do Laboratório ao longo de todo esse tempo. Este artigo apresenta parte de minha pesquisa de doutorado, em que foi necessária a discussão de certos conceitos caros à disciplina, mediante revisão bibliográfica (que não se pretende exaustiva), 
para então mergulhar no universo empírico do movimento indígena contemporâneo e suas pautas atuais ${ }^{1}$. Os autores aqui trazidos, embora sob uma ordem aparentemente aleatória, e nem sempre coabitantes frequentes dos mesmos textos, servem para traçar um caminho que é tanto lógicoconceitual quanto histórico-empírico. Priorizei também aqueles que souberam ver antes de outros a ascensão desse movimento étnico-político e contribuíram para o seu entendimento. O que ofereço aqui, no entanto, é mais uma forma de relacionar todas essas peças do que propriamente uma peça nova no tabuleiro dos estudos das relações interétnicas e do movimento indígena no Brasil.

Acredito que seja necessária uma revisão, mesmo que breve e limitadíssima, dentro do muito que já foi escrito sobre o assunto, da emergência do movimento indígena contemporâneo, sendo de grande ajuda um mergulho de cabeça nessa história indígena (menos por ser sobre os indígenas do que por ser feita por eles) que transcende barreiras disciplinares e fronteiras estatais. Não se trata, portanto, de impor noções e temporalidades alheias ao universo indígena aqui observado, mas de trabalhar justamente com os termos utilizados pelos povos indígenas para explicar e construir a sua própria história recente.

A respeito da noção de sociedades ditas "frias" - nas quais se encaixariam os indígenas, em comparação às sociedades modernas marcadas por uma percepção histórica, ou seja, "quente", de tempo -, conceito este que foi muito criticado (e mal compreendido) em Lévi-Strauss, ele mesmo esclareceu que essa oposição não dizia respeito às mudanças reais pelas quais algumas sociedades passam e outras não, mas às maneiras subjetivas com que cada uma delas concebe sua relação com a história. E prosseguiu dizendo que, naquele final de século XX em que escrevia, enquanto as sociedades modernas estariam querendo "resfriar-se" perante um futuro que não se anunciava nada promissor, estaria ocorrendo, paradoxalmente, um "aquecimento" das sociedades indígenas:

Acontece também que as sociedades frias se aquecem quando a história as arrebata e conduz. É isso que passa atualmente nas duas Américas, onde as populações indígenas rebelam-se contra o destino que lhes foi imposto pelos colonizadores, tomando consciência de seus interesses comuns, se reagrupando para defendê-los e, por vezes não sem sucesso,

\footnotetext{
${ }^{1}$ A pesquisa resultou na Tese "Acadêmicos indígenas em Roraima e a construção da interculturalidade indígena na universidade: entre a formação e a transformação", defendida no Programa de Pós-Graduação em Antropologia Social (PPGAS) da Universidade de Brasília (UnB) em 05 de maio de 2017, sob orientação do Prof. Stephen G. Baines.
} 
reivindicar as terras e liberdades perdidas. (LÉVI-STRAUSS, 1993, p. 10, em tradução livre minha).

Lévi-Strauss estava se referindo ao surpreendente crescimento do movimento indígena no período, impulsionado pela urgência de reverter as mazelas impostas pelos colonizadores. Processos de organização política de grupos indígenas até então dispersos e fragilizados frente à expansão da sociedade nacional espalharam-se pelo Brasil e por outros países, configurando um fenômeno determinante do indigenismo a partir do último quarto do século XX.

Já o indigenismo, enquanto característica típica da "antropologia periférica" realizada na América Latina, ou seu estilo, de acordo com Roberto Cardoso de Oliveira (1993), indicaria essa preocupação dos antropólogos locais com "a dimensão política das relações interétnicas" e com "o contexto nacional envolvente" (p. 27), enfatizando os dilemas específicos dessa parte do planeta, até então chamada de "Terceiro Mundo". No Brasil, os povos indígenas seriam o "outro interno", em contraposição ao outro distante, transoceânico, da antropologia praticada nos países centrais (Estados Unidos, Inglaterra e França).

Há que se diferenciar, entretanto, o indigenismo como ideologia a favor da construção da nação, mesmo que por meio de "um pensamento e uma ação pautados por um compromisso com a causa indígena" (p. 20), daquilo que vem se tornando a própria presença indígena nos espaços de atuação intelectual e política (em Associações, entidades não-governamentais, cargos públicos, Universidades, na produção artística, bibliográfica etc.) da vida nacional. O próprio Cardoso de Oliveira afirma que há, no Brasil, um indigenismo "alternativo", elaborado pelas ONGs, e que se contrapõe ao indigenismo oficial, com eventuais convergências, assim como reconhece a importância de "uma política indígena propriamente dita, criada no bojo do movimento indígena e trabalhada em seus diferentes congressos e assembleias indígenas", deixando claro assim "a diferença entre política indígena (dos índios) e política indigenista (do Estado" (p. 21).

Mesmo assim, dada sua compreensão mais ampla do que seja o indigenismo dentro da antropologia, não há como deixar de considerar este próprio artigo como inserido naquilo que Roberto Cardoso de Oliveira define como essa "ideia mais ampla, ativada sempre que se manifesta entre os antropólogos o compromisso com o destino dos povos indígenas" (p. 21). Resta, contudo, reconhecer que, ao assumirmos esse compromisso, nosso papel talvez seja o de meros coadjuvantes em um movimento que em muitos aspectos lembra o das placas tectônicas. 


\section{A noção de etnogênese}

Populações amazônicas submetidas ao longo de séculos a relações de dominação e subordinação, e que devido a esse sistema discriminatório já não se identificavam mais como indígenas - os "caboclos", ribeirinhos e os chamados "índios civilizados" - passaram a se reagrupar em torno de identidades étnicas renascidas, reconhecendo em si mesmos e sobretudo nas relações que travam entre si e com o território um diferencial marcante perante às formas convencionais da "cultura nacional". Esses processos de etnogênese são ainda hoje responsáveis pelo crescimento contínuo, desde o início desse movimento histórico ainda nos anos 1970, dos assim autodeclarados índios, cada vez mais numerosos nos censos estatais. 0 agrupamento em torno de uma identidade étnica - ou seja, em torno de um vínculo novo e ancestral ao mesmo tempo - funciona agora como um instrumento político desses povos frente às ameaças e pressões crescentes (ou em ondas, oscilando conforme os interesses dos mercados e dos projetos governamentais) sobre seus territórios e modos de vida tradicionais. Um bom exemplo descritivo desse tipo de fenômeno é trazido por Ricardo Neves Pereira (2007), em sua dissertação de mestrado, sobre a Comunidade Canafé, no rio Negro:

O engajamento no movimento etnopolítico do rio Negro é um aspecto da etnogênese regional que promove a visibilidade deste processo. É nesta conjuntura que moradores de distintas comunidades e sítios passam a re-elaborar a cultura discursivamente e afirmar os contornos de uma identidade coletiva fundamentada no parentesco, na ancestralidade e em territórios comuns[...]

A criação formal da comunidade Canafé em 1985 marcou o coroamento da primeira fase de etnificação do grupo, apresentando as bases para a consolidação das áreas de uso comum por grupos de parentes caboclos e indígenas dispersos ao longo do médio rio Negro, durante a decadência da elite extrativista. No contexto da tomada de consciência sobre a etnicidade, o "território" passa a figurar como a espinha dorsal das narrativas políticas a partir das quais os moradores da comunidade Canafé constroem a comunidade como uma unidade étnica (p. 110).

Assim também é o que demonstra João Pacheco de Oliveira (1998) a respeito do que se passou na região Nordeste do Brasil, cujos povos indígenas haviam sido relegados ao segundo plano pelas políticas estatais de 
reconhecimento e demarcação de terras assim como - infeliz coincidência - pelas principais correntes da pesquisa etnológica, sejam elas "o evolucionismo cultural norte-americano e o estruturalismo francês" ou o "indigenismo" de Darcy Ribeiro (p. 50). A partir da década de 1970, no entanto, grupos até então conhecidos como "índios misturados" ou simplesmente "índios do nordeste" passam a constituir, para si e/ou no contexto intersocietário, identidades étnicas singularizadas e distintas uma da outra, tornando visível um fenômeno que é explicado por Pacheco de Oliveira a partir do conceito de etnogênese'. Isto seria a princípio "uma contradição em termos absolutos: o surgimento recente (duas décadas!) de povos que são pensados, e se pensam, como originários" (p. 47), escrevia Pacheco em 1998, ou seja, somam-se aí mais quase duas décadas inteiras. Porém o que pode parecer um paradoxo é na verdade um processo reverso daquele a que esses grupos foram submetidos historicamente, quando tiveram suas terras tomadas e seus modos de vida alterados em razão de forças coloniais (missões religiosas, aldeamentos) e estatais (indigenismo oficial) de territorialização. A esse processo reverso João Pacheco chama também de territorialização, mas agora com outro sentido:

O processo de territorialização não deve jamais ser entendido simplesmente como de mão única, dirigido externamente $e$ homogeneizador, pois a sua atualização pelos indígenas conduz justamente ao contrário, isto é, à construção de uma identidade étnica individualizada daquela comunidade em face de todo o conjunto genérico de "índios do Nordeste". Os pajés Pankararu podem ensinar a comunidades de parentes desgarrados como se faz um "praiá" (cerimonial em que as máscaras dançam representando os "encantados"), mas cada nova aldeia (assim como cada grupo étnico dali surgido como os Pankararé, os Kantaruré e os Jeripancó) irá levantar sua própria "casa dos praiás", instituindo a sua própria galeria de "encantados" e instaurando uma relação específica com os "encantados" mais antigos (p. 60).

O fenômeno da etnogênese, como passou a ser chamado, não é exclusivo do Brasil, tendo configurado um novo despertar dos povos indígenas de todo o continente americano. O termo ethnogenesis já aparece escrito em 1975 por Gerald M. Sider, num estudo de caso sobre o povo indígena Lumbee, nos EUA, e surge como uma contraposição ao que seria o processo reverso, o

\footnotetext{
2 "É por isso que o fato social que nos últimos vinte anos vem se impondo como característico do lado indígena do Nordeste é o chamado processo de etnogênese, abrangendo tanto a emergência de novas identidades como a reinvenção de etnias já conhecidas" (PACHECO DE OLIVEIRA, 1998, p. 53).
} 
etnocídio, que Sider define como a destruição de um modo de vida no confronto de Estados-Nações com grupos étnicos. A etnogênese, por conseguinte, seria o fenômeno antagônico:

"the historical creation of a people who often begin, after generations of domination, with little more than a sense of their collective identity. Ethnic nations struggle not just to persevere and preserve, but to create"(SIDER, 1975, p. 161).

O próprio Sider faz referência a uma publicação anterior, em que o termo é utilizado por Stanley Diamond, que via a etnogênese como um "retorno dialético da etnicidade" (DIAMOND, 1974, p. 38), num processo de autoidentificação de grupos culturais que estaria se tornando permanente após uma era de preponderância do Estado-Nação burguês e de distorções provocadas pelo imperialismo e pela apropriação estatal da nação, enquanto força criativa de costumes, língua, ligação com o território etc.

Atualmente, apesar de nomear um debate contemporâneo relevante, 0 termo não deixa de produzir sentidos e efeitos diversos, incluindo certa desconfiança - para não dizer recusa -, por parte de alguns grupos indígenas, da noção de etnogênese, por sua ênfase no aspecto de invenção (ou, num sinônimo, artifício), o que contraria a ideia de um vínculo natural de sangue, com a terra, o passado etc., ou então por sugerir uma 'geração espontânea' de grupos sociais, que talvez prefiram se imaginar como resistentes do que como emergentes.

José Maurício Andion Arruti (1997), por sua vez, ao buscar proximidades e oposições entre processos de afirmação identitária de comunidades indígenas e quilombolas, e problematizando o termo "remanescentes" (de quilombos ou indígenas), lembra que, apesar de a inventividade social e a invenção da tradição serem elementos comuns a qualquer grupo humano, é preciso cuidar "para não se atribuir a esse movimento analítico um sentido negativo, associado às ideias de falsidade, manipulação, artificialismo etc" (p. 28).

Tampouco este é um fenômeno novo, apesar da surpresa que costuma gerar. Miguel A. Bartolomé (2006) traz alguns exemplos históricos da etnogênese no continente, demonstrando como diversos grupos étnicos se formaram enquanto muitos outros desapareceram - a partir do encontro colonial, "devido a deslocamentos, congregações e alianças" (p. 42), como é o caso dos Mískito e dos Garífuna no Caribe, que se fundiram com grupos de escravos de origem africana fugidos para se constituírem enquanto etnias ainda nos séculos XVII e XVIII, respectivamente. Mesmo após o período 
colonial, muitas dessas alianças foram feitas com fins militares no enfrentamento à expansão dos novos Estados e de suas burguesias crioulas.

Assim, em vez de manterem a crença romântica em sociedades "puras" e estáticas, diversos povos indígenas atualmente existentes são exemplos de etnogênese, segundo Bartolomé, "ao produzirem um novo sujeito coletivo previamente inexistente como tal, embora potencialmente contido em uma configuração cultural"(p. 43).

O interesse pelo assunto tampouco é algo novo: $O$ antropólogo brasileiro Ruy Coelho, ainda nos anos 40 do século XX, desenvolveu notória pesquisa sobre "os Karaíb negros de Honduras" (como ele se referiu aos Garífuna) e sua emergência como um grupo étnico distinto e independente, "a partir dos contatos entre os índios karaíb e escravos fugitivos da ilha de São Vicente, no século XVII"(COELHO, 1964, p. 16). Coelho via os Garífuna em um processo de adaptação contínua, em que instituições culturais indígenas, africanas e europeias misturam-se para configurar a cultura dos "karaíb negros", uma resultante do encontro colonial avassalador. Para Coelho, a cultura dos Garífuna seria

encarada como respostas coletivas estruturadas para fazer face ao desafio das circunstâncias históricas, para os meios adotados por uma etnia para atingir a homoestasis cultural $e$ social, por assim dizer, que os capacitou a sobreviver ao impacto dos acontecimentos que causaram a extinção de seus hospedeiros, os karaíb "vermelhos" e de quase todos os grupos indigenas do Caribe (p. 21).

Em casos recentes como o dos Cocama, na fronteira entre Brasil (rio Solimões), Peru e Colômbia, assim como daqueles povos indígenas do Nordeste brasileiro, julgados desaparecidos, o ressurgimento de grupos identitários indígenas até então adormecidos sob a denominação misturados, mestiços ou caboclos coloca em questão justamente o adjetivo "novo" atribuído a esses sujeitos coletivos, uma vez que se tratam de "aparentes etnogêneses que não seriam senão o reaparecimento da mesma sociedade com outro rosto cultural ou com outro nome"(BARTOLOMÉ, 2006, p. 49).

Pode-se falar, nesses casos, de uma continuidade não-linear dos povos indígenas, o que não é nenhuma contradição; ao contrário, é algo próprio da forma indígena de estar no e de compreender o mundo, condizente com o modo de contar as narrativas tradicionais e histórias míticas. Nada mais arbitrário, portanto, do que esperar deles a linearidade de um romance realista ou de uma apostila de história. 


\section{Etnicidade e Povos Indígenas}

Os estudos do contato interétnico têm como nomes mais reconhecidos Roberto Cardoso de Oliveira ([1964] 1996; 1976), com as pesquisas que partem da noção de friç̧ão interétnica; e Frederick Barth, em especial por seu livro Ethnic Groups and Boundaries (BARTH, 1970). Ambos os autores adotam uma postura anti-essencialista e fronteiriça na forma de olhar para os grupos indígenas ou tribais, uma vez que estes seriam constituídos menos por uma essência interior do que através de suas relações com outros grupos externos. Entretanto, enquanto Barth está interessado em situações de "complementariedade" étnica ${ }^{3}$, a abordagem de Cardoso de Oliveira aplica-se especificamente ao contato entre um determinado grupo indígena amazônico e o Estado nacional, prevalecendo em sua visão não a complementariedade, mas a desigualdade de forças e posições inerente a esse tipo de relação.

Seguindo a linha adotada por Cardoso de Oliveira, Manuela Carneiro da Cunha (2009), em textos dos anos 1970 e 1980 por ela republicados sobre etnicidade e política, afirma que os traços diacríticos de uma cultura podem receber novos significados quando levados a exercer uma função distintiva e contrastiva em relação a outros grupos - o que se evidencia nas relações com os mecanismos classificatórios e "objetificantes" do Estado. Não há como falar, portanto, em critérios culturais para identificar a etnicidade ou para definir quem é ou não é indígena, uma vez que tal dilema é resolvido por Carneiro da Cunha de maneira simples e enfática:

é índio quem se considera e é considerado índio. Portanto, os Pataxó são índios porque assim se consideram, não obstante ostentem uma cultura forjada, precisamente criada para afirmá-lo (p. 238).

Essa afirmação não deve ser mal interpretada. Em vista do que se lhes é exigido, os grupos indígenas precisam hoje "representar-se" como imagem exagerada do que já são, mas nós (um "nós" genérico enquanto sociedade/Estado nacional) não vemos. Não deixa de haver, mais do que fingimento, certo didatismo para conosco nessas versões simplificadas de

\footnotetext{
${ }^{3}$ Cabe lembrar que Fredrick Barth, orientado por Edmund R. Leach em Cambridge, fora influenciado pela crítica deste ao funcionalismo de Malinowski e Radcliff-Brown, assim como pela preferência de Leach pelo dinamismo histórico e pelo desequilíbrio social em lugar da "coleção de borboletas" que atribuía às classificações e comparações das diferentes sociedades. Leach, entretanto, não via as reconfigurações sociais enquanto respostas ao colonialismo europeu, demonstrando que a instabilidade das estruturas gumsa devia-se às pressões decorrentes de estarem situadas entre um modelo hierárquico (Shan) e outro igualitário (Gumlao), mas igualmente "nativos" - formando assim um sistema estrutural. Barth acabou, em sua análise das fronteiras étnicas no Paquistão, levando à frente algumas das propostas apresentadas na "teoria da mudança social Kachin" que Leach expôs em Sistemas políticos da Alta Birmânia. Talvez por isso Barth tenha dado prioridade a relações interétnicas não marcadas pela presença colonial do Estado.
} 
suas práticas e "culturas com aspas". Dado o grau de obviedade a que chegam alguns exemplos, é de supor que sejamos péssimos alunos.

No presente, afirma Miguel Bartolomé, a constituição de novos sujeitos coletivos, que passam a se auto-intitular como um todo Povos Indígenas, visa a somar forças para adquirir melhores possibilidades de êxito no confronto político com o Estado e seu "mito da miscigenação". Em um texto escrito no calor dos acontecimentos da década de 1980, sobre grupos étnicos e o Estado, David Maybury-Lewis questiona a ideia de que a etnicidade indígena seria uma ameaça aos governos latino-americanos, sobretudo em países que, como no Brasil, a população indígena configura uma fração mínima do total:

"Será que, realmente, sentem na etnicidade indígena uma ameaça ao Estado? Este argumento poderia ter alguma plausibilidade em países como a Bolívia, o Peru ou a Guatemala, onde a grande maioria das populações é de ascendência indígena. Mas será que as medidas tomadas pelo regime de Pinochet no Chile para desmembrar as comunidades da minoria indígena Araucana e destruir sua cultura podem ser explicadas da mesma maneira? Será que os índios Miskito da Nicarágua realmente constituem uma ameaça para o Estado? E o que dizer do Brasil, onde os índios são no total uma fração de um por cento da população e vivem na sua maior parte em áreas longínquas do país? (...)Eles não representam uma ameaça física ao estado brasileiro, mas um desafio ideológico. Tradicionalmente, o Brasil tem-se comprometido com a autoimagem do cadinho de raças, um país que herdou $e$ desenvolveu a habilidade lusitana de fundir diferentes raças num só povo. A demanda dos índios de serem aceitos como brasileiros mantendo, todavia, suas culturas indígenas, desafia esta enraizada auto-imagem, pois repousa na crença de que o Brasil deveria ser uma sociedade plural e multi-étnica" (MAYBURY-LEWIS, 1985, p. 107-8).

As tentativas estatais de superar as configurações étnicas incluíam também os governos de esquerda do continente, que visavam a transformar as populações indígenas em algo próximo de "sindicalistas campesinos", como ocorreu na Bolívia em 1952. Os revolucionários socialistas também não estiveram a salvo "da 'cegueira ontológica' construída pelas ideologias nacionalistas estatais"(BARTOLOMÉ, 2006, p. 45) ou, no caso, pela ideologia da luta de classes, para a qual as diferenças étnicas e culturais eram vistas 
como dispersivas e superficiais - quando não meras ideologias que mascaravam a opressão econômica ${ }^{4}$.

Os diferentes grupos indígenas em processo de reafirmação étnica trazem em si dinâmicas internas próprias, que passam a reconhecer umas nas outras o substrato de uma experiência comum: o colonialismo 'interno" imposto pelos Estados e pelo mercado. Longe de uma dispersão, entretanto, a questão identitária e cultural veio acompanhada de uma forte e renovada consciência política.

Ronald Niezen (2003) vê a organização política em torno da categoria "Povos Indígenas" como um fenômeno global, argumentando que "um produto da globalização é a revolta contra as forças de uniformidade cultural e contra a apropriação da soberania dos povos indígenas pelos Estados" (p. 02, em tradução aproximada minha). O termo "Povos Indígenas", de fato, surge como um conceito jurídico no século XX na arena global de convenções e tratados internacionais da ONU, principalmente de um de seus órgãos, a Organização Internacional do Trabalho (OIT), que o usa desde a Convenção 107 de 1957. Atualmente em todo o mundo, estima-se que o termo "Povos Indígenas" abarque algo em torno de 4 mil grupos distintos, num total de 300 milhões de pessoas, em todos os continentes e não apenas os "índios" das Américas. Os encontros e fóruns globais de lideranças indígenas, como os promovidos pela ONU, são hoje um importante espaço de construção e fortalecimento mútuo das organizações e causas indígenas locais frente aos assédios de Estados e indústrias. Mais do que uma categoria jurídica ou analítica externa, cada vez mais a identidade indígena é usada com orgulho e afirmação por aqueles coletivos humanos que resistem ao colonialismo e à exploração de suas terras ancestrais (NIEZEN, 2003).

Niezen não deixa de notar a peculiaridade de que um conceito novo se refira a uma identidade primordial e a modos de vida que remetam a tempos imemoriais. Afirma, porém, que apesar de ser rara a criação de um novo tipo de entidade política global, também o nacionalismo e os Estados nacionais surgiram como novidades no século XIX, mas igualmente se imaginaram e se constituíram com base em "laços naturais, pátrias permanentes, culturas arcaicas e vínculos atemporais de história comum"(p. 03). Assim como o nacionalismo o foi dois séculos atrás, o indigenismo seria um movimento global que ganhou impulso nas últimas décadas. Porém Niezen faz questão de deixar clara a diferença entre povos indígenas e a noção de grupo étnico (categoria analítica, mas não de afirmação), e sobretudo de

\footnotetext{
${ }^{4}$ Sobre o caso específico do desentendimento dos sandinistas com os Miskito, na Nicarágua, e sobre o posicionamento marxista ortodoxo de que as identidades étnicas serviriam para mascarar a desigualdade de classes, esta sim fundamental, ver também Maybury-Lewis, 1985.
} 
etnonacionalismo, que é quando há pretensões de se constituir a formaEstado enquanto meta final de libertação de uma coletividade, que se afirma a partir de fortes traços culturais e linguísticos distintivos daquele Estado que até então a engloba e de que faz parte, geralmente enquanto grupo minoritário local.

A visão de Ronald Niezen, apesar de muito esclarecedora em vários aspectos na compreensão do movimento indígena (que ele chama de indigenismo) enquanto fenômeno global e recente, é demasiadamente adaptada, para não dizer entusiasmada, com a ideia "pós-moderna" de superação dos Estados nacionais enquanto fenômenos ultrapassados (do século XIX) de organização política. Os Estados, assim, estariam perdendo espaço e poder de influência frente à globalização e sobretudo às organizações de direito internacional, que por sua vez constituiriam a arena contemporânea por excelência do indigenismo. Escrito no início dos anos 2000, parece-me que seu livro representa bem a sensação de que se estava entrando realmente em uma "nova ordem mundial", ideia que vem sofrendo algumas reviravoltas nos últimos anos, sobretudo nos países sulamericanos, mas não apenas.

Os nacionalismos e o protagonismo dos Estados, que pareciam coisas superadas apenas quinze anos atrás, voltaram com força ao centro da arena política global recentemente, seja em patriotismos de direita ou em populismos de esquerda. Ao mesmo tempo, dão a impressão de que não têm mais a capacidade real de oferecer respostas plausíveis e soluções suficientes para os novos (?) problemas que prometem enfrentar: crise dos refugiados, desastres naturais, migrações, xenofobia e racismo crescentes, neopopulismos, terrorismo, vigilância policial e da internet, crise financeira global, são hoje importantes temas de debate entre candidatos a governante e pautas permanentes do noticiário nacional e internacional.

Na América do Sul a organização dos povos indígenas representa uma "questão" tanto internacional quanto interna, assumindo contornos étnicopolíticos diversos dependendo do contexto local. Em certos países, como Bolívia e Equador, essa nova consciência política fez com que a mobilização indígena ganhasse forças até então sem precedentes e se voltasse para a tomada do Estado por uma população indígena e "mestiça" que passava a se ver como, ao mesmo tempo, originária e majoritária. Bolívia e Equador, respectivamente em 2007 e 2008, promulgaram novas constituições em que se autodeclaram Estados Plurinacionais, reconhecendo-se como sociedades multiétnicas e culturalmente diversificadas. Na Bolívia, a eleição de Evo Morales em 2005 faz dele o primeiro Presidente indígena na história, e mesmo em um país de maioria indígena tal fato foi visto com 
surpresa, provocando ceticismo em outros países e questionamentos ilegítimos e ações violentas por parte das oligarquias locais que se recusavam a reconhecê-lo.

Novas Constituições nacionais gestadas no fim do século $\mathrm{XX}$, como a brasileira (1988), a colombiana (1991) e a venezuelana (1999), acompanhadas de acordos internacionais como a Convenção 169 da OIT, firmada em 1989, ampliaram consideravelmente os direitos indígenas nesses países, desencadeando processos de construção de políticas estatais diferenciadas, como é o caso da saúde indígena e da educação escolar bilíngue. Esse novo quadro político regional despertou a preocupação de elites, militares e governantes, receosos de possíveis "ameaças" que poderiam dele advir. Um exemplo é a insólita publicação, no início do governo Lula, da I Reunião de Estudos: Ascensão de Movimentos Indigenistas na América do Sul e Possíveis Reflexos para o Brasil, realizada pelo Gabinete de Segurança Institucional da Presidência da República em 2004. Nessa reunião, foram convidados especialistas para apresentarem a situação da "questão indígena" em países como Colômbia, Venezuela ${ }^{5}$ e Bolívia. Sobre o primeiro, escreveu Claudia Leonor López-Garcés (2004):

...é importante ressaltar que, a partir da década de oitenta, na Colômbia, iniciam-se diferentes processos de reetnização ou reindigenização de diversos grupos que, ainda tendo fortes ligações históricas e culturais com povos indígenas, tinham adotado um estilo de vida próprio da população camponesa do País. Esses processos de velamento das identidades étnicas foram gerados, em grande parte, devido à extinção dos territórios de resguardos, como fenômeno que afetou o sul do País desde os anos vinte, intensificando-se nas décadas de quarenta e cinquenta. Em alguns casos, inclusive setores de população afro-colombiana têm expressado o desejo de fazerem parte da organização política dos povos indígenas, procurando também ser reconhecidos como tais (p. 14).

Gersem dos Santos Luciano Baniwa (professor da Universidade Federal do Amazonas e o primeiro indígena com doutorado em antropologia no Brasil, orientado por Stephen G. Baines na Universidade de Brasília (UnB) e antigo membro do LAGERI), por sua vez, percebe que os povos indígenas estão hoje

\footnotetext{
${ }^{5}$ Quem ficou responsável por falar sobre "o caso da Venezuela" foi o prof. da Universidade Federal de Roraima (UFRR) e antigo membro do LAGERI, Maxim Repetto, que logo se prontificou a negar qualquer influência negativa das organizações indígenas venezuelanas sobre o outro lado da fronteira, mais especificamente sobre os indígenas de Roraima. Pelo contrário, Repetto argumentou que ocorre uma troca de experiências positivas entre os Pemon nos dois países, sendo que ao invés de apresentarem alguma ameaça à ordem nacional, "o que eles solicitam e exigem é a participação real e 'não apenas no papel'" (REPETTO, 2004, p. 54) nos destinos do país.
} 
vivendo um momento histórico importante de reelaboração da consciência étnica e da autoestima indígena, uma recuperação do orgulho nativo e da cidadania, acompanhada da retomada de tradições que estavam deixando de ser praticadas, devido ao preconceito e perseguições que sofriam. A emergência dos movimentos indígenas contemporâneos articula, portanto, aspectos tradicionais das suas culturas com técnicas e reivindicações modernas, como nas lutas pela reconquista das terras indígenas, por serviços diferenciados de educação e saúde, pelo etnodesenvolvimento, entre outros, que aliam saberes internos e externos às comunidades. Esses saberes, como perceberam os indígenas, não são auto-excludentes. Vejamos o que Gersem Baniwa diz sobre o momento que se vivia pouco mais de 10 anos atrás:

Os povos indígenas do Brasil vivem atualmente um momento especial de sua história no período pós-colonização. Após 500 anos de massacre, escravidão, dominação e repressão cultural, hoje respiram um ar menos repressivo, o suficiente para que, de norte a sul do país, eles possam reiniciar e retomar seus projetos sociais étnicos e identitários. Culturas e tradições estão sendo resgatadas, revalorizadas e revividas. Terras tradicionais estão sendo reivindicadas, reapropriadas ou reocupadas pelos verdadeiros donos originários. Línguas vêm sendo reaprendidas e praticadas na aldeia, nas escolas e nas cidades. Rituais e cerimônias tradicionais há muito tempo não praticados estão voltando a fazer parte da vida cotidiana dos povos indigenas nas aldeias ou nas grandes cidades brasileiras (BANIWA, 2006, p. 39).

Inicialmente, a mobilização em torno da identidade indígena deu-se sem que fosse promovida voluntariamente por políticas de Estado, isso quando ela não representou justamente o efeito oposto daquele pretendido pelos governos $^{6}$, qual seja, a dissolução dos diversos grupos indígenas na identidade nacional via ocupação e eliminação de seus territórios

\footnotetext{
${ }^{6}$ Quem traz um claro exemplo sobre o caso brasileiro de tentativa de desindianização que "saiu pela culatra" é Eduardo Viveiros de Castro (2006), ao relembrar o projeto de emancipação que a ditadura militar tentou implementar para, ao estabelecer "quem não era mais índio", retirar a tutela sobre os indígenas e, por consequência, a proteção legal sobre suas terras: "No fundo, não deixou de ser uma sorte os generais e coronéis da época terem tentado desindianizar uma porção de comunidades indígenas, pois isso, na verdade, terminou foi por reindianizá-las. A atabalhoada tentativa da ditadura de legiferar sobre a ontologia da indianidade 'desinvisibilizou' os índios, que eram virtualmente inexistentes como atores políticos nas décadas de 1960 e 1970. Eles só apareciam, de vez em quando, em alguma reportagem colorida sobre o Xingu, geralmente como ilustração do admirável trabalho dos irmãos Villas Bôas (digo admirável sem nenhuma ironia; não deixava de ser bizarro, porém, o fato de que havia nessa época uma série de jornalistas especializados em embasbacar-se diante dos Villas Bôas e outros sertanistas). A grita suscitada com o projeto de emancipação resgatou a questão indígena do folclore de massa a que havia sido reduzida. Ela fez com que os próprios índios se dessem conta de que, se eles não tomassem cuidado, iam deixar de ser índios mesmo, e rapidinho" (p. 04).
} 
tradicionais, quando não sua destruição física. A organização do movimento indígena é, portanto, anterior às ampliações institucionais de direitos promovidas pelos Estados, pois estes é que tiveram que se adequar à nova configuração social do fim do século e às pressões dela advindas. No entanto, as mudanças nas políticas estatais também foram um importante vetor de fortalecimento do movimento indígena, seja ao tentarem impor um modelo contra o qual era preciso se organizar, seja ao passarem a fornecer instrumentos antes inexistentes para a consolidação de discursos identitários e para a formação de quadros indígenas, que é impulsionada principalmente com a construção da escola indígena diferenciada.

O professor de ciência política na University of Notre Dame, Guillermo Trejo, escreve sobre essas transformações ocorridas na América Latina (AL), retomando autores e hipóteses anteriores para dar conta dos acontecimentos. Segundo ele, intelectuais do quilate de Guillermo Bonfil Batalla, Rodolfo Stavehagen e Xavier Albó sugerem que os efeitos imprevistos das políticas agrárias e indigenistas e dos governos populistas nos países da AL tenham favorecido a irrupção do movimento indígena:

Ainda que, na maioria dos países, as políticas indigenistas tenham por objeto a assimilação da população indígena à hegemonia mestiça, ao receber um tratamento diferenciado, as populações indígenas sempre estiveram conscientes de sua diferença étnica. Paradoxalmente, as políticas indígenas mantiveram, ao contrário de seus objetivos, o indigenismo como um fator latente para a mobilização social. Com a promoção da educação bilíngüe, os governos latinoamericanos criaram involuntariamente uma nova elite indígena preparada por professores bilíngües (TREJO, 2006, p. 241).

Guillermo Trejo chama esse período iniciado na década de 1970 de "quarta onda de mobilizações indígenas na América Latina" ", uma noção que ele pega emprestado de outros autores para pôr em debate suas possíveis explicações causais desse movimento histórico. Dentre as hipóteses debatidas, além das políticas desastradas dos governos latino-americanos e dos efeitos inesperados da escola bilíngue, está o papel da Igreja Católica,

\footnotetext{
${ }^{7}$ As ondas anteriores teriam ocorrido ao longo do (e como resistência ao) processo de conquista do continente, respectivamente no séc. XVI, no fim do séc. XVIII e entre a metade do séc. XIX e o início do XX. Trejo destaca ainda outras situações expressivas desta onda mais recente: "A proliferação de organizações maias na Guatemala nos últimos anos, a sublevação indígena no Equador, em 1990, e o surgimento do Exército Zapatista de Libertação Nacional (EZLN) no México, em 1994, [que] despertaram um interesse pouco usual em relação à temática indígena" (TREJO, 2006,p. 227).
} 
ou melhor, de sua corrente progressista, na organização das comunidades indígenas até então dispersas e enfraquecidas. Como resume Trejo:

Para muitos estudiosos do ressurgimento do indigenismo na América Latina, o papel desempenhado pela Igreja Católica progressista no meio indígena é fundamental para se entender as origens da "quarta onda". Nas zonas rurais de alta concentração indígena na Guatemala, na Bolívia, na Colômbia, no Equador e no México, o clero católico desenvolveu discursos ideológicos que revalorizam as línguas e culturas autóctones, $e$ estratégias pastorais que favoreceram a organização social das populações indígenas (p. 241).

No Brasil, as primeiras assembleias indígenas - que viriam a formar o embrião de organizações formalmente constituídas - foram organizadas ainda nos anos 1970 por um braço da Igreja Católica, o Conselho Indigenista Missionário (CIMI), criado em 1972. Alcida Ramos (1997) relata que o surgimento do CIMI decorreu do

"profundo engajamento de membros da Igreja com a Teologia da Libertação, segundo os moldes que também inspiraram as Comunidades Eclesiais de Base em centros urbanos e a Comissão Pastoral da Terra no campo"(p. 02).

Nas primeiras assembleias que organizaram, em 1974 no Mato Grosso e em 1975 no Pará, conta Ramos, o CIMI providenciava toda a infraestrutura do evento, possibilitando encontros e trocas de experiências que de outro modo não seriam possíveis. Isso acabou ensejando um "cosmopolitização" (p. 05) a partir da qual o movimento indígena pôde caminhar com suas próprias pernas. Ramos narra como se deu essa fase inicial da "descoberta" de um destino comum entre grupos indígenas que mantinham pouco ou nenhum contato entre si:

As espantosas semelhanças no modo como, um após outro, todos os grupos indígenas sofriam nas mãos de brancos tocaram uma corda ressonante na consciência dos participantes. O sentimento de partilhar os mesmos problemas com outros índios até então desconhecidos gerou um forte espírito de solidariedade e de confiança advindo da consciência de que, afinal, eles não estavam sós em seu infortúnio. Agora poderiam contar uns com os outros na luta por uma vida melhor. Um novo mundo de injustiça generalizada abriu-se para eles, criando um sentimento de companheirismo que se mantinha mesmo depois de 
terminadas as assembléias. Ao contrário de fases posteriores do movimento em que líderes indígenas se dirigiam diretamente ao homem branco, os discursos nessas primeiras reuniões eram para ser ouvidos por companheiros índios numa troca direta de desventuras[...]. Conforme a consciência política dos índios ultrapassava o âmbito dos problemas regionais e alcançava o nível nacional, as assembléias começaram a chamar a atenção das autoridades, em especial da Fundação Nacional do Índio - FUNAI - que se opunham frontalmente aos esforços do CIMI. Várias assembléias indígenas foram perturbadas ou mesmo proibidas pela FUNAI ou pela polícia federal durante o regime militar (p. 03).

A reação do Estado contra o CIMI não tardou, com a repressão e proibição das assembleias e ataques a seus membros, sendo uma triste ironia que durante a Assembleia Nacional Constituinte (ANC), entre 1987 e 1988 - logo após o término de uma ditadura que durara mais de vinte anos -, o discurso oficial tenha contado com a ajuda de um jornal chamado Estadão (O Estado de São Paulo) para atacar, com um dossiê cheio de informações falsas, o trabalho do CIMI - que tentava emplacar o termo Nações Indígenas na Carta Magna - junto aos povos indígenas (RAMOS, 1997, p. 06-8). A ideia de que o Estado brasileiro poderia ser concebido como tendo em seu interior nações indígenas, ou seja, enquanto um autêntico "Estado Plurinacional" (como ocorreu vinte anos mais tarde na Bolívia e no Equador) provocou as mais destemperadas reações nos governantes e generais da época, como demonstrou Ramos, e continua a alimentar ainda hoje os pesadelos nacionalistas daqueles que dizem defender a "soberania nacional".

Tanto que o termo "Nações" foi abandonado pelo movimento indígena no Brasil, que o considerou um desgaste desnecessário e uma causa impossível - ou até indesejável, quando se ouve de lideranças indígenas que os "brasileiros" de verdade são eles, nós é que viemos de fora, isto é, de outros países. Tais temores de um suposto "separatismo" indígena, apesar de alguns boatos que já circularam na internet, nunca encontraram qualquer fundamento em fatos reais ou em discursos e projetos políticos dos próprios indígenas que, ao contrário, costumam cobrar maior presença e efetiva atenção do Estado brasileiro para a proteção de suas terras e seus direitos.

Ao retomar as origens do movimento indígena no Brasil, Alcida Ramos destaca ainda um episódio muito significativo para a época e também para o tema deste artigo: a criação da União das Nações Indígenas (UNI), em 1980, na Capital Federal, que se deu por iniciativa de "um grupo independente de 
jovens índios de diversas etnias (Terena, Xavante, Bororo, Pataxó e Tuxá) que estudavam em Brasília"(Ramos, 1997, p. 03). O protagonismo indígena, ou sua "agencialidade", como Ramos iria escrever mais tarde (RAMOS, 2010), estava já nesse momento ligado umbilicalmente à educação formal, que funcionava como uma mola propulsora das reivindicações indígenas, formando lideranças que se tronariam nomes reconhecidos na luta pelos direitos indígenas que tomou aquela década, culminando com a Constituição Federal de 1988.

Como se vê, portanto, a ampla mobilização em torno dos direitos indígenas na Constituinte é a demonstração cabal de que o movimento indígena não dependia de apenas um único fator de mobilização, mas contava com uma extensa rede de aliados que incluía políticos, antropólogos, juristas, jornalistas, religiosos, entre muitos outros apoiadores, sem esquecer do protagonismo que as próprias lideranças indígenas exerceram durante todo o processo.

\section{Considerações finais}

Após esta retomada de um tema um tanto espinhoso e que desperta as mais variadas e contundentes reações, favoráveis e contrárias - seja por parte de representantes ou agentes do Estado, de acadêmicos ou de membros de organizações indígenas e indigenistas -, percebe-se que noções como etnogênese e mesmo movimento indígena têm sua força justamente do calor que ainda guardam e do viço que demonstram no que se refere à contemporaneidade dos fenômenos que procuram descrever. Isso não quer dizer que estas sejam novidades ainda esperando por interpretação, mas ao contrário, parece que etnogênese e movimento indígena são dessas noções conceituais que interagem intensamente com o "mundo real" e com as pessoas "de carne e osso" que fazem parte do panorama abordado, num processo raro de retroalimentação entre o meio acadêmico e o campo termo aqui utilizado não só no sentido empírico, mas campo de lutas políticas e embates diários.

Tal interação, por sua vez, não necessariamente é de confirmação e de reprodução mútua, estando talvez aí sua grande riqueza: ela é válida mesmo quando esse campo concreto reage e rejeita os termos propostos pela academia. Talvez seja isso o que permite chamar a antropologia e o nosso procedimento de pesquisa de dialéticos: trata-se de um aprendizado recíproco (e não um antagonismo) entre agentes envolvidos na história, ainda que não do mesmo lado. 


\section{Bibliografia}

ARRUTI, José Maurício Andion. A emergência dos "remanescentes": notas para o diálogo entre indígenas e quilombolas. Mana 3(2):7-38, 1997.

BANIWA, Gersem dos Santos Luciano. O índio brasileiro: o que você precisa saber sobre os povos indígenas no Brasil de hoje. Brasília: UNESCO, 2006.

BARTH, Fredrick. Ethnic groups and boundaries: the social organization of culture difference. Bergen - Oslo: Universitets Forlaget; London: George Allen \& Unwin, 1969 - Reprint 1970.

BARTOLOMÉ, Miguel Alberto. As etnogêneses: velhos atores e novos papeis no cenário cultural e político. Mana 12(1): 39-68, 2006.

CARDOSO DE OLIVEIRA, Roberto. [1964] O índio e o mundo dos brancos - $4^{\mathrm{a}}$ Ed. Campinas, SP: UNICAMP, 1996.

. O movimento dos conceitos na antropologia. Revista de Antropologia, v. 36, p. 13-31, São Paulo, USP, 1993.

Identidade étnica, identificação e manipulação. In CARDOSO DE OLIVEIRA, Roberto. Identidade, etnia e estrutura social. São Paulo: Pioneira, 1976.

COELHO, Ruy. Os Karaíb Negros de Honduras. Revista do Museu Paulista, Volume XV, p. 7-212, São Paulo, 1964.

CUNHA, Manuela Carneiro da. Cultura com aspas e outros ensaios. São Paulo: Cosac Naify, 2009.

IAMOND, Stanley. In Search of the Primitive: A Critique of Civilization. New Brunswick: Transaction Books, 1974.

LÉVI-STRAUSS, Claude. Un autre regard. In: L'Homme, 1993, tome $33 \mathrm{n}^{\circ} 126-$ 128. La remontée de l'Amazone. pp. 7-11.

LÓPEZ-GARCÉS, Cláudia Leonor. A questão indígena na Colômbia: movimentos indígenas, políticas indigenistas e conflito armado. In REPÚBLICA FEDERATIVA DO BRASIL / GABINETE DE SEGURANÇA INSTITUCIONAL / SECRETARIA DE ACOMPANHAMENTO DE ESTUDOS INSTITUCIONAIS. I Reunião de Estudos: Ascenção de Movimentos Indigenistas na América do Sul e Possíveis Reflexos para o Brasil. Brasília, Gabinete de Segurança Institucional; Secretaria de acompanhamento de estudos institucionais, 2004.

MAYBURY-LEWIS, David. Vivendo Leviatã: grupos étnicos e o Estado, 103118, Anuário Antropológico/83. RJ: Tempo Brasileiro; Fortaleza: UFC, 1985. 
NIEZEN, Ronald. The origins of indigenism: human rights and the politics of identity. Berkeley and Los Angeles: University of California Press, Ltd., 2003.

PACHECO DE OLIVEIRA, João. Uma etnologia dos "índios misturados"? Situação colonial, territorialização e fluxos culturais, Mana 4(1): 47-77 (1998).

PEREIRA, Ricardo Neves Romcy. Comunidade Canafé: história indígena e etnogênese no médio rio Negro. Dissertação de mestrado em Antropologia Social. PPGAS/UnB. Brasília, 2007, 165 páginas.

RAMOS, Alcida Rita. Revisitando a etnologia à brasileira. In MARTINS, Carlos Benedito; DUARTE, Luiz Fernando Dias. Horizontes das ciências sociais no Brasil: antropologia. São Paulo: ANPOCS, 2010.

Convivência interétnica no Brasil: os índios e a nação brasileira. (Trabalho apresentado no Simpósio Internacional "Autonomías étnicas y estados nacionales" organizado por Alicia Barabas e Miguel Bartolomé, Oaxaca, México, 25-27 de junho de 1997). Série Antropologia, 221. Brasília, DAN/UnB, 1997.

REPETTO, Maxim. Ascenção dos movimentos indígenas na América do Sul e possíveis reflexos para o Brasil: o caso da Venezuela. In REPÚBLICA FEDERATIVA DO BRASIL / GABINETE DE SEGURANÇA INSTITUCIONAL / SECRETARIA DE ACOMPANHAMENTO DE ESTUDOS INSTITUCIONAIS. I Reunião de Estudos: Ascenção de Movimentos Indigenistas na América do Sul e Possíveis Reflexos para o Brasil. Brasília, Gabinete de Segurança Institucional; Secretaria de acompanhamento de estudos institucionais, 2004.

SIDER, Gerald M. Lumbee Indian cultural nationalism and ethnogenesis (Case study). Dialectical Anthropology, p. 161-172, 1975.

TREJO, Guillermo. Etnia e mobilização social: uma revisão teórica com aplicações à "quarta onda" de mobilizações indígenas na América Latina. In DOMINGUES, José Maurício; MANEIRO, María (Orgs.). América Latina hoje: conceitos e interpretações; tradução Silvia de Souza Costa. Rio de Janeiro: Civilização Brasileira, 2006.

VIVEIROS DE CASTRO, Eduardo. "No Brasil todo mundo é índio, exceto quem não é". In RICARDO, Beto; RICARDO, Fany (edição geral). Povos indígenas no Brasil:2001/2005. São Paulo: Instituto Socioambiental (ISA), 2006. 